\title{
Cátedra patrimonial Margarita Tortajada Quiroz
}

\section{Patrimonial lectureship Margarita Tortajada Quiroz}

\author{
Ramón M. Trejo-Carrillo ${ }^{a}$, Beatriz J. Galindo-Zavala ${ }^{b}$, Cynthia J. Pérez-Antúnez ${ }^{c}$
}

\begin{abstract}
:
The Patrimonial Lectureship Margarita Tortajada Quiroz is an academic activity held every two years and focused on Dancing by Universidad Autónoma del Estado de Hidalgo. This university recognizes Margarita Tortajada's career and looks forward to strengthen the dancers training through practice and research. Also to held activities where personalities in the dancing scene join together not only in research but also in creation and education. In this text you will find the activities held in 2021, during its second issue.
\end{abstract}

Keywords:

cathedra, lectureship, Margarita Tortajada, dance, creation, research.

\section{Resumen:}

La Cátedra Patrimonial Margarita Tortajada Quiroz es una actividad académica bianual enfocada en la danza e impulsada por la Universidad Autónoma del Estado de Hidalgo. En ella se reconoce la trayectoria de la Dra. Margarita Tortajada y se busca fortalecer la formación dancística desde la práctica y la investigación, así como llevar a cabo actividades donde confluyan personalidades de la escena dancística tanto en el ámbito de la investigación, como en el de la creación y la docencia. En este texto se presentan las actividades que fueron llevadas a cabo en 2021, durante su segunda emisión.

\section{Palabras Clave:}

cátedra, Margarita Tortajada, danza, creación, investigación.

\section{Introducción}

La Cátedra Patrimonial Margarita Tortajada es un evento académico dedicado a la danza que se ha llevado a cabo a partir de 2019 en la Universidad Autónoma del Estado de Hidalgo (UAEH) a través del Grupo de Investigación "Danza, sociedad e inclusión", la Licenciatura en Danza del Instituto de Artes, y, por supuesto, por la Dra. Margarita Tortajada Quiroz, quien es investigadora del Centro Nacional de Investigación, Documentación e Información de la Danza "José Limón" del Instituto Nacional de Bellas Artes y Literatura (INBAL). En esta Cátedra se reconoce el trabajo y trayectoria de la Doctora, así como también se busca impulsar y distinguir la labor investigativa dentro de la comunidad dancística. La Cátedra es un evento planeado académicamente por la Dra. Margarita, en el cual todas las actividades responden a temas de actualidad y permiten la confluencia de grandes personalidades de la danza y de la investigación.

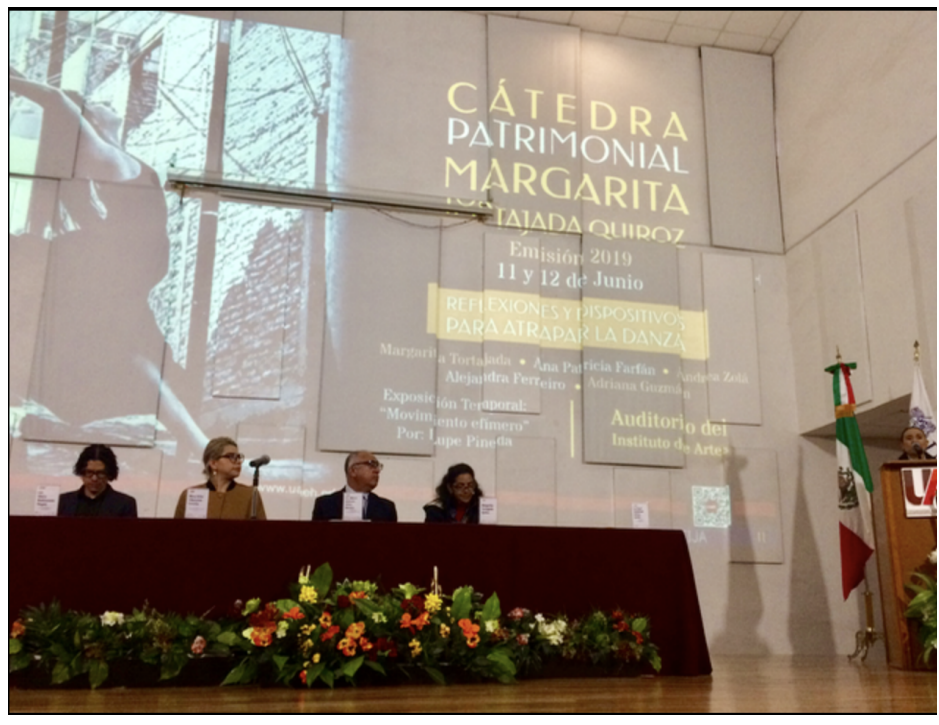

Cátedra Patrimonial Margarita Tortajada, 2019

Foto: Alejandra Zamora

\footnotetext{
${ }^{a}$ Ramón Miguel Trejo Carrillo, https://orcid.org/0000-0003-2516-5314, Email: ramon_trejo2192@uaeh.edu.mx

${ }^{\mathrm{b}}$ Beatriz Julieta Galindo Zavala, https://orcid.org/0000-0002-5760-365X, Email: beatriz_galindo@uaeh.edu.mx

c Cynthia Jeannette Pérez Antúnez, https://orcid.org/0000-0003-1969-9424, Email: cynthia_perez@uaeh.edu.mx
} 
En:

https://www.uaeh.edu.mx/gaceta/1/numero5/julio/catedra. $\underline{\mathrm{html}}$

Durante el evento inaugural de la primera emisión en 2019, que llevó por título "Reflexiones y dispositivos para atrapar la danza", la Doctora comentó: "es un honor inmenso para mí que la primera Cátedra Patrimonial dedicada a la Danza lleve mi nombre, [...] mi agradecimiento es por defender un espacio académico para la danza, para su reflexión y su práctica, para la formación de jóvenes en un arte digno y una profesión digna".

En aquel momento el evento se llevó a cabo de manera presencial y además de las conferencias magistrales impartidas por la Dra. Margarita, también se contó con la participación de las investigadoras: Alejandra Ferreiro, Ana Patricia Farfán y Adriana Guzmán. Posteriormente en 2021, y a consecuencia de la pandemia ocasionada por el SARS-CoV-2, las actividades fueron realizadas totalmente en línea mediante transmisiones sincrónicas y asincrónicas en las plataformas Zoom, YouTube y Facebook. La cátedra en su segunda emisión llevó por título "La composición coreográfica y la danza folclórica escenificada: abordajes y aproximaciones".

\section{LA COMPOSICIÓN COREOGRÁFICA Y LA DANZA FOLCLÓRICA ESCENIFICADA: ABORDAJES $Y$ APROXIMACIONES}

El 7 de junio de 2021, después de la bienvenida de la Mtra. Erika Liliana Villanueva Concha, actual directora del Instituto de Artes de la UAEH, dieron inicio las actividades con la conferencia inaugural: "Trazos de la obra coreográfica de Amalia Hernández" compartida por la Dra. Margarita Tortajada.

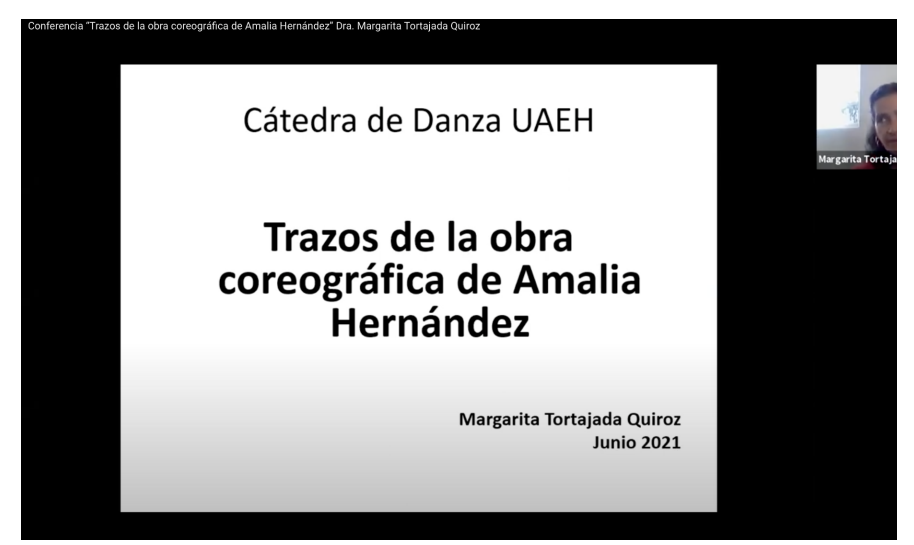

Conferencia inaugural. Cátedra Patrimonial Margarita

Tortajada, 2021

Foto: Extraída de YouTube

https://www.youtube.com/watch?v=7EvBoCLOTiA

A lo largo de dos días, se llevaron a cabo otras tres conferencias y dos talleres. "Conceptos, clasificaciones y categorías aplicadas a la danza folclórica" fue el nombre de la conferencia impartida por el Mtro. Raúl Valdovinos de la Universidad Autónoma de Baja California. EI Mtro. Juan Carlos Palma, de la Escuela Nacional de Danza Folklórica del INBAL, impartió la tercera conferencia: "Reposición, apropiación y download. Rutas sobre el proceso de creación de La otra propuesta: memoria e identidad en la danza folclórica contemporánea". La última conferencia fue dictada por el Mtro. Carlos Nieves de la Academia de la Danza Mexicana del INBAL, la cual llevó por título "Recuento histórico de la producción coreográfica de la danza folclórica escénica".

Los talleres fueron realizados en dos sesiones, una por día. El primero fue "Zapateo Contemporáneo. Pulso, Comunión, Autonomía, Emancipación", impartido por el Mtro. Miguel Pérez García, músico, bailarín y coreógrafo independiente del proyecto artístico "Don Cañalero". El segundo taller fue "Laboratorio teórico-práctico de composición coreográfica", impartido por la Mtra. Adriana León y el Mtro. Alejandro Vera de la Universidad Autónoma de Colima.

Dentro de las reflexiones surgidas a partir de la segunda emisión, podemos destacar el trabajo de Miguel Pérez García, quien con generosidad compartió el trabajo intelectual y físico que ha hecho con "Don Cañalero". Puntualizó la importancia de la reflexión, más aún en un tiempo pandémico, donde el intercambio está mediado por la tecnología. Mencionó que dentro del proceso de enseñanza aprendizaje se requiere entrega, insistencia y paciencia, sobre todo porque la forma de intercambio nos subraya el trabajo en solitario. De tal manera que surgen interrogantes como ¿por qué seguimos aquí "conectados" ?, ¿para qué lo hago?, ¿cuál es el sentido de lo que estoy haciendo?, ¿vale la pena seguir haciéndolo? De estas interrogantes se desprenden los conceptos de repetición, precisión y perfección, pues, en palabras de Miguel Pérez, si bien "en el cuerpo humano no habita la perfección", la repetición con consciencia permite ir consolidando el trabajo técnico en una suerte de actividad preprogramada que a su vez incrementa las posibilidades psicomotrices de quien baila.

Por otro lado, la Mtra. Adriana León y el Mtro. Alejandro Vera a través de su Taller- laboratorio de Composición Coreográfica, nos permitieron reflexionar sobre las posibilidades creativas en la Danza Folclórica. En este sentido, la Mtra. Adriana retomó las palabras de la Dra. Margarita puntualizando: "hay tantas formas de abordaje de la danza folclórica como personas que la realizan". Asimismo, ofrecieron una perspectiva clara para abordar la composición coreográfica desde el trabajo docente tanto práctico como conceptual. Fue aludido el trabajo de la Técnica RAZA del Mtro. Rafael Zamarripa como un ejemplo de acercamiento creativo en la Danza Folclórica. También nos invitaron a reflexionar sobre las convenciones escénicas que van determinando en alguna medida nuestra forma de relacionarnos con la danza y las artes en general. Respecto al trabajo corporal sugerido en este taller, el maestro Alejandro Vera comentó: "cuando estoy en estas exploraciones busco momentos y ritmos distintos a lo ya conocido, para que eso sea un detonante exploratorio que me ayude a salir de las convenciones e innovar en mi propio abordaje". El Mtro. Raúl Valdovinos mencionó que, si bien el objeto de estudio de esta Cátedra es la composición coreográfica y la danza folclórica escenificada, existen 
infinitas posibilidades de abordajes y aproximaciones. Por tal razón considera que es imperante identificar, analizar y poner en práctica aquellas aportaciones conceptuales, clasificaciones y categorías que nos ayuden a aclarar el panorama, a ordenar las ideas, ubicar y relacionar las otras disciplinas dancísticas y formas de cultura relacionadas con la danza folclórica.

De acuerdo con la aportación e interpretación personal del Mtro. Valdovinos, hay tres autores que rompieron paradigmas y al mismo tiempo dieron identidad a su forma de concebir a la danza folclórica; el primero, Rafael Zamarripa, el segundo, Alberto Dallal y el tercero Ramiro Guerra. Ellos, además de su amplia producción artística y bibliográfica, han propuesto categorías, términos y conceptos que permiten analizar los fenómenos dancísticos folclóricos desde tres ángulos: coreográfico, genealógico y evolutivo.

Por otra parte, el Mtro. Carlos Nieves nos compartió una revisión histórica sobre algunos procesos de producción coreográfica en el campo de la danza folclórica. Habló sobre la consolidación del campo de representación escénica del campo tradicional y popular en México durante la segunda mitad del siglo $X X$, específicamente en la Cd. de México y con la Academia de la Danza Mexicana y el INBAL. En este contexto se veía a la danza folclórica desde una perspectiva sólida, consolidada y no había cambios significativos de ningún sentido. Hace mención al rompimiento con la forma de estas prácticas consolidadas que surgen a finales del siglo $X X$ y principios del $\mathrm{XXI}$, las cuales se perfilan con la materialización de prácticas de un campo expandido y tienen que ver con un folclor que inclusive puede no verse como tal.

En relación con las diferentes propuestas que han surgido en torno a la danza folclórica, el Mtro. Valdovinos y el Mtro. Nieves, mencionaron a Amalia Hernández y su Ballet Folklórico de México como pioneros de la danza folclórica escenificada. Una segunda propuesta mencionada fue la de Rafael Zamarripa con el Ballet Folclórico de la Universidad de Colima y su forma de escenificar el folclor desde la base de su técnica RAZA. El Mtro. Juan Carlos Palma habla sobre su propia propuesta, en la cual hace la investigación de diferentes grupos folclóricos consolidados y busca hacer un rompimiento con el trabajo escénico de los mismos para construir algo nuevo. Por último, mencionaron la propuesta de Miguel Pérez García, "Don Cañalero", y su Zapateo Contemporáneo, así como a Paula Herrera con su Compañía Danzariega.

Todas las actividades fueron conducidas por el Mtro. Alejandro Moya, docente del Instituto de Artes de la UAEH. La clausura del evento se llevó a cabo con la participación del Coordinador interino de la Licenciatura en Danza de la UAEH, el Esp. Ramón Miguel Trejo Carrillo.

\section{CONSIDERACIONES FINALES}

\footnotetext{
* Cabe mencionar que estas transmisiones siguen en la red de forma permanente, así que se puede acceder a ellas en cualquier momento (ver el listado final del repositorio).
}

Las y los estudiantes de la Licenciatura en Danza del Instituto de Artes de la UAEH, así como la planta docente y la comunidad en general que participó de las transmisiones de la Cátedra Margarita Tortajada por las redes sociales*, se vieron beneficiadas en más de un sentido. Los vínculos entre la danza folclórica mexicana y la danza contemporánea se abordaron en profundidad desde las perspectivas histórica, creativa, escénica, metodológica e incluso curricular. ¿Qué impacto puede tener esto en la formación de las nuevas generaciones de bailarines y coreógrafos? Para empezar, los diálogos entre la tradición y la innovación se hicieron evidentes, no solamente en las propuestas actuales, sino también desde las pioneras. El desglose de las clasificaciones, influencias, producciones, colaboradores, corrientes, sujetos, escuelas, géneros y estratos, brindado por cada uno de los participantes en la Cátedra, podemos tomarlo como una cartografía a recorrer para encontrar puntos de encuentro y desencuentro propiciadores de nuevos procesos.

La investigación en danza permite precisamente eso, situarnos y problematizar nuestro quehacer en ella más allá del cuerpo en movimiento. Le da sentido profundo al contexto, a las formas y al rompimiento de las mismas.

Invitamos a todas las personas lectoras de estas líneas a recorrer estos trazos epistemológicos que la Cátedra Margarita Tortajada Quiroz nos brinda por tiempo indefinido en las ligas que presentamos en el repositorio. Por último, reafirmamos que nos sentimos afortunados por contar bianualmente con la siempre generosa presencia de la Dra. Margarita Tortajada en nuestra institución, como una posibilitadora de vínculos y deconstrucción. Incansablemente nos demuestra que el cuerpo es a la vez archivo de movimiento y de conocimiento.

\section{REPOSITORIO DE LA CÁTEDRA MARGARITA TORTAJADA, 2021}

1.- Inauguración de la Cátedra Patrimonial Margarita Tortajada 2021. Participantes: Dra. Margarita Tortajada, Mtra. Erika Liliana Villanueva y Mtro. Adolfo Pontigo: https://www.youtube.com/watch?v=k2wlZUXA3MA

2.- Conferencia Trazos de la obra coreográfica de Amalia Hernández. Impartida por la Dra. Margarita Tortajada Quiroz: https://www.youtube.com/watch?v=7EvBoCL0TiA 
3.- Conferencia Conceptos, clasificación y categorías de la Danza Folklórica. Impartida por el Mtro. Raúl Valdovinos: https://www.youtube.com/watch?v=qcCaVJNynA8

4.- Conferencia Recuento histórico de la producción coreográfica de la danza folclórica escénica: Impartida por el Mtro. Carlos Nieves: https://www.youtube.com/watch?v=1qWsPRaKFKg

5.- Conferencia Reposición, Apropiación y Download: Rutas sobre el proceso de creación de la otra propuesta: Memoria e identidad en la danza folklórica contemporánea. Impartida por el Mtro. Juan Carlos Palma: https://www.youtube.com/watch?v=Jng4L7QL23Q

6.- Taller "Zapateo contemporáneo. Pulso, Comunión, Autonomía, Emancipación". Impartido por el Mtro. Miguel Pérez: https://www.youtube.com/watch? $\mathrm{v}=$ fsqRwo Adwc $\quad($ sesión 1) y https://www.youtube.com/watch?v= qmgfVNuQOQ (sesión 2).

8.- Taller laboratorio Composición coreográfica. Impartida por Adriana León y Alejandro Vera: https://www.youtube.com/watch?v=YgurgcYit1k (sesión 1) y https://www.youtube.com/watch?v=LVCvxghkFdU (sesión 2).

10.-Clausura de la Cátedra Margarita Tortajada Quiroz. Por la Dra. Margarita Tortajada y el Esp. Miguel Trejo: https://www.youtube.com/watch?v=T0nqHrxapx4 